\title{
Digital Media Literacy to Higher Students in Indonesia
}

\author{
Lucy Pujasari Supratman ${ }^{1}$, Aep Wahyudin ${ }^{2}$ \\ ${ }^{1}$ Department of Communication, Telkom University, Indonesia \\ ${ }^{2}$ Department of Communication and Broadcasting, Bandung Islamic State University, Indonesia
}

\begin{abstract}
The easiness of media internet usage has given positive impact to the society. Nevertheless, internet has also held inevitable negative excess. The lack of digital media literacy education shall become requirement to the rises of horribly phenomenon in Indonesia. Noticing to the information technology based university in Bandung City, Telkom University is the only University which applies the Internet Digitalization System on daily academic routinely. Every student has digital personal student account to facilitate academic activities. However, there aren't much research discussing about Digital Media Literacy to students social media usage. The purpose of this study is to create the awareness on using social media smartly. I used qualitative method with descriptive case study approach. The result was from 160 students that had been taken through purposive sampling (81 students have more than 5 active social media), they didn't comprehend the use of social media wisely. Since the Collaborative Learning Model of Digital Media Literacy of Digital Media Literacy was applied for one full semester in Communication Management Class to 4 classes of third semester higher students, their mindset about Digital Media Literacy meaning had shifted into the wiser social media users.
\end{abstract}

Keywords-Digital Media, Education, Higher Students, Internet, Literacy.

\section{INTRODUCTION}

There are almost half of the Indonesia citizen total amount use internets. The easiness in getting internet facility and affordable price of internet package which offered by some providers, have increased Indonesia internet users both young children and elderly. People of Indonesia can access the internet freely as it called a freedom of expression. Each generation age can have their voices through internet media.

A survey from The Nielsen Global Generational Style (2015) elaborated the generation stages of digital literacy by involving 30,000 respondents from 60 countries. They are Generation Z (age 15- 20 ), Millennial Generation (age 21-ᄀ34), Generation X (Age 35-ᄀ49), Baby Boomers (age 50--64), and Silent Generation (age > 65). Generation Z, Millennial Generation and Generation X are referred to be the most familiar generation with the gadgets. But the most internet familiar among those generations are Generations $\mathrm{Z}$ and Millennial Generation. They have been using the internet access on their mobile phone as part of their lives. It will be very common things to find Generation $\mathrm{Z}$ and Millennial Generation look busy interacting on their mobile phone. They can hold bowing their head down and push the touch screen button to communicate in cyber world for hours. These are serious problems that face by young generation. Based on my previous pre observation in the field, they do not entirely understand social media etiquette. The lack of digital literacy skill to use the Internet safely will provide the teenagers mind set against negative impact of internet in social media. It is likely to Brosdahl and Carpenter's (2011) research which categorized the internet generations through the birth year. They divided the generations into Silent Generation (1925-1945), Baby Boomers (1946-1960), Generation X (1961-1981) and Generation Y (born after 1981) and Generation Z. In the research of Immordino-Yang et al (2012), Generation Y and $\mathrm{Z}$ are very often exposed to internet technologies that have the implications to their cognitive, emotional and social interactions. In their research, the generation $\mathrm{Y}$ and $\mathrm{Z}$ are very dependent to find entertainment and communicate with their friends through internet medium. This study emphasizes internet usage basis to current young generation. Generation Y, Generation Millennial and Generation $\mathrm{Z}$ are called digital generation as a research that has been conducted by Pempek et al (2009). They explained that the young generation spends a lot of time on consuming much content in social media. Park et al (2009) has also done similar research to the young digital generation. They stated about the function of internet usage for the digital generations are to seek information and entertainment. There is a bit different with Valkenburg et al research result (2006) to the young people internet usage. They use internet (social media) to socialize and share stories in a virtual community group. Seeing the data (IBRAF, 2017) of Internet development users in Indonesia, it has been growing fast. Let us take a look at this official chart below: 
INDONESIA REACHED 133 MILLION INTERNET USERS IN 2016

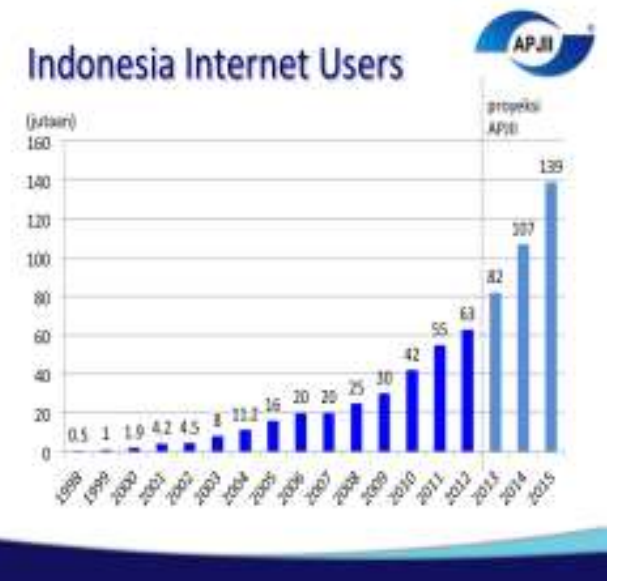

Source: International Proceeding of $5^{\text {th }}$ Annual Meeting International Broadcasting Authority Forum (2017)

The rapid advancement of digital communication technology led to two gaps between positive benefits and negative impacts. Supratman (2017) wrote cases about the malpractice of internet usage by teenagers. She clipped the cases from Pikiran Rakyat Daily Newspaper entitled "Prostitusi Online di Bandung Terungkap (Online Prostitution in Bandung is Revealed)" on March 2, 2016 edition. Its online prostitution used social media to offer online dating.

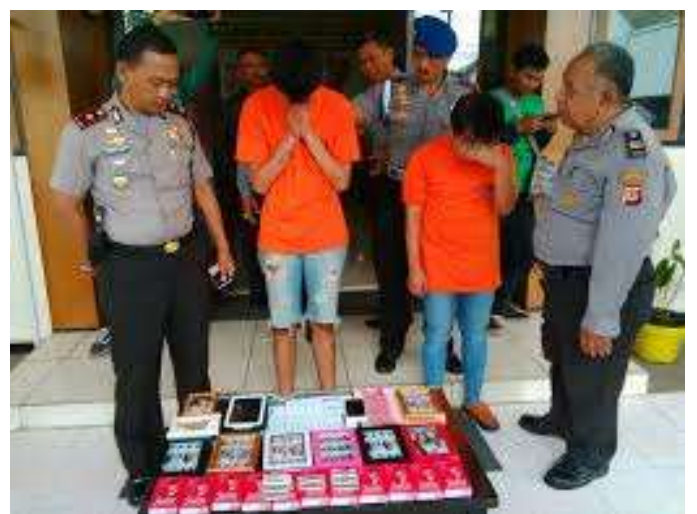

Source: Pikiran Rakyat Daily Newspaper on March 2, 2016

Beside that, there was also a higher student who ever posted about awful status in her Path social media about Yogyakarta. BBC news reported that Florence Sihombing, a graduate student of the University of Gadjah Mada, has written on her Path account that she expressed her anger over an incident at a gas station. Her Path account content was, "Jogja is poor, idiotic, uncivilized. Friends from Jakarta and Bandung don't stay in Jogja. Jogja residents are all bastards".

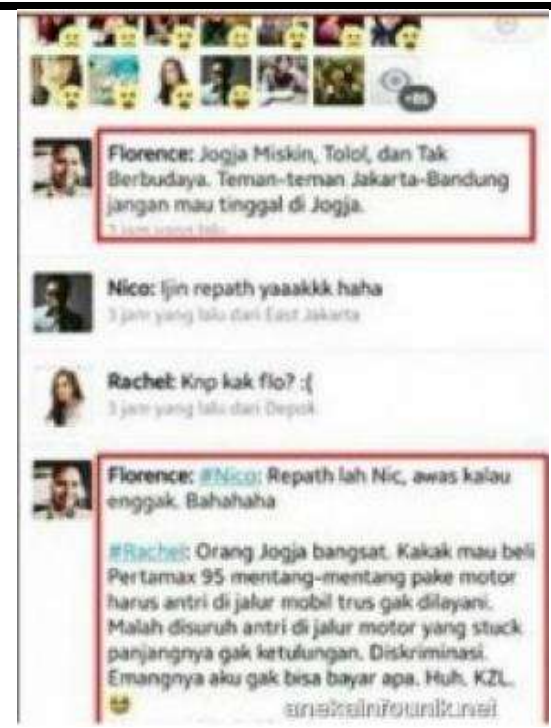

Source: http://medan.tribunnews.com

She was proven guilty of violating Article 27 (3) and Article 5 (1) of Law No.11/2008 on information and electronic transactions committing criminal deeds by posting on a social media site in September 2014 for insulting remarks about Yogyakarta and its residents. In the early 2017, a teenager named Haikal has succeeded to hack popular online ticket booing sites. He has become a criminal with giving a great loss of 307.000 US \$ (Rp. 4.1 Billion). $\mathrm{He}$ is a professional online gamer that spend most of his time in a online gaming. Based on the Jakarta Post news online (Police mulls hiring arrested hacker, Fiday April 7, 2017), said that: "The arrested suspect is a junior high school graduate who reportedly spends most of his day in front of a computer screen as a professional online gamer."

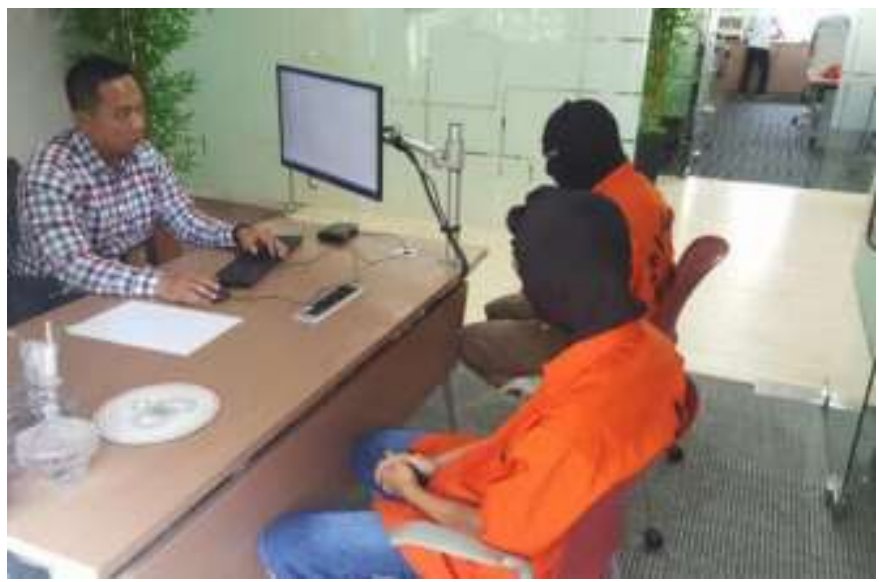

Source: http://jakartaglobe.id/news

Not only in Indonesia, a United States of America newspaper 'Independent' coverage the news entitled " $U S$ teenager's family say he died after taking part in 'Blue Whale' suicide game". Worley (2017) reported that the teenager body of Isaiah Gonzales, 15 years old was found 
hanging in a cupboard with a mobile phone set up nearby to apparently broadcast his death.

"A teenager died after taking part in an online suicide game called the 'Blue Whale Challenge,' his family have said. The Blue Whale Challenge is an unsubstantiated phenomenon, whereby participants are said to be guided through a series of tasks over 50 days, such as self-harming and watching horror films all night, culminating in a suicide." (Worley, 2017).

Technology is just merely a technology which containing part of advance software component. If it comes to meet the fact that establishing secure online communication requires high costs for personal online security. So, it is necessary to conduct a research that can prevent young internet users to be irresponsible users and ensure their safety when they are communicating in digital world.

I have chosen 160 population total informants. They are first year university students who become part of the pilot project in applying the Collaborative Talk model. This model has just been discovered by me in a one semester observing their social media posts. It performed an effective digital literacy in using the internet. They begin to be more critical as they expose or post anything in social media. The selection of Telkom University students are due the academic online system in Telkom University. The highest students of Telkom University have been very expert in using high technology gadget because their all academic systems are connected to the internet. They are accustomed to access the internet for everyday academic activities which are provided by the campus (such as academic online system, digital open library system, digital attendance list system and high speed Wi-Fi internet access).

The purpose of this study is to provide teenagers awareness about the importance of using the internet. I want to explore their understanding of internet utilization for everyday use. The research focus object is not focusing on internet technology beyond their academic activities. But it is more personal than that. I will go deep down to the usage of their personal social media purposes. It keeps focusing the digital literacy in the usage of social media in their own activities and the ethics of using social media when they are interacting in cyberspace.

\section{LITERATURE REVIEW}

Michaël Opgenhaffen and An-Sofie Claeys (2017) research results of this investigation, they conclude that companies in Belgium do in fact consider the importance of dialogue in the business context and the opportunities that social media provide in this regard. Nevertheless, organizations feel that it is important to draft social media guidelines. Even though respondents indicated that they wanted to formulate these guidelines in a positive manner, they are mainly aimed at reducing risks (e.g.guideline to not disseminate confidential information or express negative feedback about one's company) instead of promoting the appropriate use of social media in the business context.

Hannah Gomez Farias, AnnPaskor dan WalterE.Block (2017) Social media has a potent opportunity in this regard to foster change and give a voice to independent parties and individuals. If people think the two-party system is distasteful and not addressing their concerns, they can start ablog or join a like-minded forum. In the 2012 presidential election, the USA saw a surge of popularity for the libertarian-minded Ron Paul as a result of his strong online presence.Onalargerscale, we saw social media's impact in the Arab Spring that began in late 2010. It was instrumental in providing a platform where non-government conformists could coordinate demonstrations and encourage social action. Social media fomented an enormous destabilizing effect in the shaky Middle Eastern authoritarian regimes. The moment their leaders lifted their previous iron control, the people rose against them through their most accessible outlet:social lmedia. Renato Hübner Barcelos and Carlos Alberto Vargas Rossi (2014). This study has made use of qualitative methods to assess the behavior of adolescents using social media and to propose a model of outcomes and behavioral strategies which they use. While the use of two distinct techniques (focus groups and in-depth interviews) has allowed for the comparison and triangulation of data, the qualitative nature of the study limits the generality of the results. Moreover, the analysis presented here is based on a study of adolescents in Brazil and relates primarily to the features of this particular setting. Another limitation of the study relates to its concentration on the impact of social media on adolescents' social relationships, through an examination of the paradoxes of technology. Although this approach has made it possible to reveal a range of positive and negative consequences of social media, as well as the dual association between them, it did not as certain the full extent of the impact of social lmedia. For example, negative consequences of excessive social media use for time spent with family, on academic work or sleeping, as well as addictive behaviors, are possibilities which are not explored in this study, but which may occur among certain individuals and, therefore, deserve further investigation.

Ruth N. Bolton, A. Parasuraman, Ankie Hoefnagels, Nanne Migchels, Sertan Kabadayi, Thorsten Gruber, Yuliya Komarova Loureiro and David Solnet (2017). Prior research on the social media use of Generation Y 
raises more questions than it answers. It: focuses primarily on the USA and/or (at most) one other country, ignoring other regions with large and fast-growing Generation Y populations where social-media use and its determinants may differ significantly; tends to study students whose behaviors may change over their life cycle stages; relies on self-reports by different age groups to infer Generation Y's social media use; and does not examine the drivers and outcomes of social-media use. This paper's conceptual framework yields a detailed set of research questions. This paper provides a conceptual framework for considering the antecedents and consequences of Generation Y's social media usage. It identifies unanswered questions about Generation Y's use of social media, as well as practical insights for managers. Naomi Amofah-Serwaa and Perpetua S. Dadzie (2015) The study explores the implication of social media use on child behaviour in a basic school in Ghana. A survey was conducted among pupils, teachers and parents of the school. Fifty-six pupils were served with questionnaires while ten teachers and 22 parents were interviewed. The findings reveal that Facebook is the most preferred social media site. About half the pupils indicated that the models they observe on social media sites have not affected their behaviour. Some positive implications reported by parents and teachers include improvement in reading habits, dressing and communication. Negative implications also reported involve distraction of pupils' attention from their studies, frequent use of Pidgin English as well as unnecessary fashion consciousness. The study recommends that parents should visit their children's online friends to see what they post and receive from friends. Furthermore, teachers must explain the advantages and danger of using social media to children and advise them of beneficial sites to visit.

\section{RESEARCH METHODOLOGY}

I used qualitative method with descriptive case study approach. The result was from 160 students that had been taken through purposive sampling, I took 81 students who have more than 5 active social media as the sample (key informants). While the supported informants are the rest of population with only 2-3 active social media.

In the first day of observation, I gain all data from 160 students in each class. After all the data gathered, I selected the students who are active as social media users with 5 applications. The total chosen informants are 81 students. From over 81 informants, I held specific FGD at the end of the class approximately 30 minutes each class meeting. I also ask their account names they use for their social media. The FGD of Collaborative Talk run for 4 months (12 times after the class-meetings). In the time of FGD, I also did the online observation by seeing the status and post they share during this ongoing research. The collaborative talk is a comprehend discussion that comes from the internet phenomenon both from positive or negative issues. They put their own issues to be discussed openly in 30 minutes Collaborative Talk session. Collaborative talk in this reseach means every students can share their opinions, arguments, and criticism of an issue.

\section{These Are The Issues We Have Been Through During The Collaborative Talk Model To Shape Digital Literacy Among Students:}

\begin{tabular}{|c|c|c|}
\hline Observation & Week & Thematic \\
\hline $\begin{array}{c}\text { Participant } \\
\text { Observation } 1\end{array}$ & 1 & $\begin{array}{l}\text { Social Media in Indonesia, } \\
\text { Asia and Europe. }\end{array}$ \\
\hline $\begin{array}{c}\text { Participant } \\
\text { Observation } 2\end{array}$ & 2 & $\begin{array}{c}\text { Teenagers and Social Media } \\
\text { Usage Addict }\end{array}$ \\
\hline $\begin{array}{c}\text { Participant } \\
\text { Observation } 3 \\
\text { and } \\
\text { Online } \\
\text { Observation } 1\end{array}$ & 3 & $\begin{array}{c}\text { Selebgram with bad influence: } \\
\text { AnyaGeraldine, Awkarin, } \\
\text { ahsan FX, aldirachena94, } \\
\text { mimi peri }\end{array}$ \\
\hline $\begin{array}{c}\text { Participant } \\
\text { Observation } 4 \\
\text { and } \\
\text { Online } \\
\text { Observation } 2\end{array}$ & 4 & $\begin{array}{l}\text { Selebgram with good } \\
\text { influence: ClairineClay, } \\
\text { Shireeenz, devinaaureel, } \\
\text { d_kadoor, riaricis1795, }\end{array}$ \\
\hline $\begin{array}{c}\text { Participant } \\
\text { Observation } 5\end{array}$ & 5 & $\begin{array}{l}\text { Youtuber: rezaoktovian, } \\
\text { edhozell, chandraliow, Fathia } \\
\text { Izzati 'Kittendust', }\end{array}$ \\
\hline \multicolumn{3}{|l|}{$\begin{array}{c}\text { Online } \\
\text { Observation } 3\end{array}$} \\
\hline $\begin{array}{c}\text { Participant } \\
\text { Observation } 6\end{array}$ & 6 & $\begin{array}{c}\text { Vlogger: Raditya Dika, } \\
\text { Salshabila Andriani, Eka } \\
\text { Gustiwana, Arief 'Poconggg' }\end{array}$ \\
\hline Online & & Muhammad, Kaesang \\
\hline Observation 3 & & Pangarep, \\
\hline $\begin{array}{c}\text { Participant } \\
\text { Observation } 7\end{array}$ & 7 & $\begin{array}{l}\text { Public Display Affection } \\
\text { (PDA) in social media }\end{array}$ \\
\hline \multicolumn{3}{|l|}{$\begin{array}{c}\text { Online } \\
\text { Observation } 4\end{array}$} \\
\hline $\begin{array}{c}\text { Participant } \\
\text { Observation } 8\end{array}$ & 8 & $\begin{array}{l}\text { Narcism of selfie (self-portrait } \\
\text { photograph) and wefie (self- } \\
\text { portrait photograph) with two }\end{array}$ \\
\hline Online & & or more people \\
\hline \multicolumn{3}{|l|}{ Observation 5} \\
\hline $\begin{array}{c}\text { Participant } \\
\text { Observation } 9\end{array}$ & 9 & $\begin{array}{c}\text { Online Shopping, Hoax, } \\
\text { Cyber bullying and Stalking }\end{array}$ \\
\hline Online & & \\
\hline
\end{tabular}




\begin{tabular}{|c|c|c|}
\hline Observation 6 & & \\
\hline $\begin{array}{l}\text { Participant } \\
\text { Observation } \\
10\end{array}$ & 10 & $\begin{array}{l}\text { Relationship in Social Media: } \\
\text { Unfollow, Unfriend, Business } \\
\text { of buy and sell followers }\end{array}$ \\
\hline $\begin{array}{l}\text { Participant } \\
\text { Observation }\end{array}$ & & $\begin{array}{l}\text { Regulation and Information } \\
\text { Technology Law }\end{array}$ \\
\hline $\begin{array}{c}\text { Participant } \\
\text { Observation } \\
11\end{array}$ & 11 & Ethics in Social Media \\
\hline $\begin{array}{c}\text { Participant } \\
\text { Observation } \\
12\end{array}$ & 12 & $\begin{array}{l}\text { Feedbacks of Last Meeting } \\
\text { from all informants }\end{array}$ \\
\hline
\end{tabular}

Source: Research Modification (2017)

In the beginning of observation, the informants didn't comprehend the use of social media wisely. Since the Collaborative Learning Model of Digital Media Literacy was applied for 12 weeks, their mindset about Digital Media Literacy had shifted into the wiser social media users. They now also turned their social media account in private mode for the security. I use snowball sampling technique to collect the informants. The data are taken from 81 students. Based on the data analysis from 81 informants, it has been found that Instagram is in the first position on student's social media selection. There are 80 students chose Instagram to be part of their active account. These are the list of social media the students actively use for their daily activities:

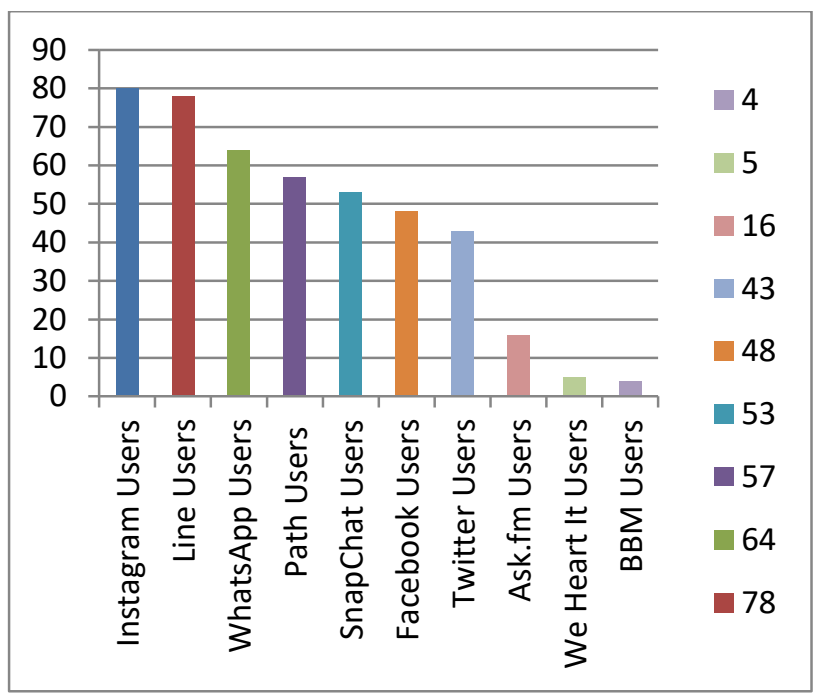

Source: Research Modification (2017)

Seeing the data above, I focused on the informants Instagram account to do the online observation. There are 80 Instagram users that have been the informants. They will be comprehended through the Collaborative Learning Model of Digital Media Literacy of digital literacy. The target research is to put the deep understanding in using social media user wisely through this model.

\section{FINDING AND DISCUSSION}

The adolescence is the development age of human where their curiosity level of things culminated. They love to do the challenging things and are proud to declare it. Without the self-awareness within themselves and guidance, they could be fall apart to any negative actions. Moreover, the advancement of technology has put them in rapidly cyber world traffic. They can interact freely with everyone and every stuff. The intensive literacy digital guidance by making them aware of being smart social media users will save them to be involved in cybercrime. Cybercrime has many undercover motives that can drag the students into the cybercriminal, both as the victim or the intender.

Basically, the internet technology function is used to develop knowledge and broaden the insight. Nowadays, most adolescence (informants) in this research utilize it to find entertainment, run an online business, collect their hobby information, order online transportation and organize their daily activities. There is so much positive impact on the use of internet. However, they do not really protect themselves and understand the usage of social media comprehensively.

These are the table of their non-understandable about the social media usage.

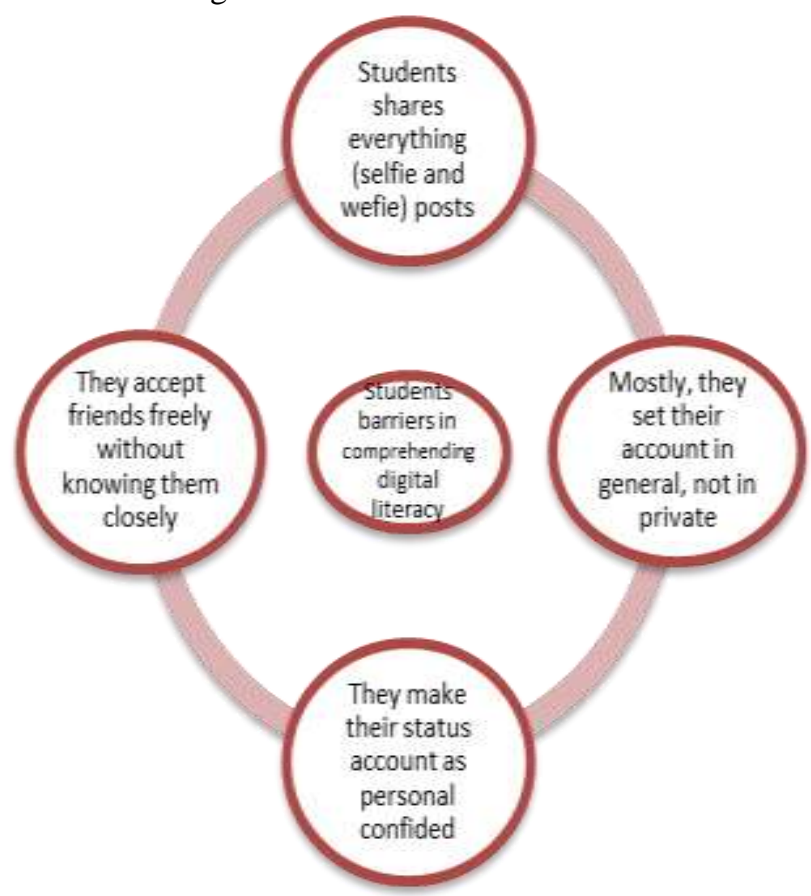

Source: Result Model (2017)

The observation is divided into 12 meetings. At the beginning observation, I was surprised that they know a lot of well-known Selebgram, Youtuber and Vlogger rather than television celebrity. However, they barely concern about the data percentage of internet user in Indonesia, Asia and Europe. They just know about the 
trends of social media which boomed in Indonesia. Once they figure out the account, they download the account without reading the term and condition of the account. If the account has many downloaders, then they turn into the newest account. I was trying to open their minds about the current data of internet users in Indonesia. Indonesia is in the third country of internet user's position before China and India. I get this data below from the international conference of IBRAF.

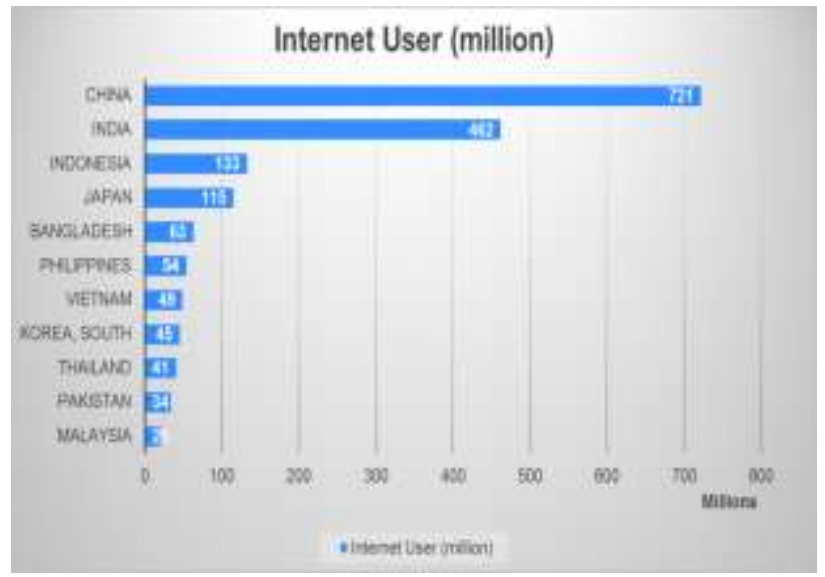

I gained their curiosity through the open discussion among informants. As the discussion was taking over by the informants, I just remain to be silent. Every participant observation that I took with the informants, their responses were good.

All students joined the discussion actively. When some students spoke, the other listened. They listened to give the feedback of what to be discussing in the session. The agreement and disagreement ever aroused in the collaborating discussion. It was happened when they discussed the Selebgram with bad influence: AnyaGeraldine, Awkarin, ahsan FX, aldirachena94, mimi peri and Selebgram with good influence: ClairineClay, Shireeenz, devinaaureel, d_kadoor, riaricis1795. I divided the inforants into to groups. The first group contain the students who agree with AnyaGeraldine, Awkarin, ahsan FX, aldirachena94, mimi peri posts. While the second group contain the student who agree with ClairineClay, Shireeenz, devinaaureel, d_kadoor, riaricis1795. It is the time for me to neutralize the condition again.

I act only as the moderator to start the collaborating discussion and close it by sending (conclude the discussion) them the message to be a wiser digital native. They find their own truths about which Selebgrams are the best profile to be followed. I shape their awareness slowly to get a real understanding about being smart social media users. The next observation is discussing the inspiring Youtuber and Vlogger. Having the inspiring
Youtuber and Vlogger will let them know what not to be post and what to be post. These observations continued to discuss Public Display Affection (PDA) in social media, Narcism of Selfie, Online Shopping, Hoax, Cyber bullying, Stalking and Relationship in Social Media. Stanley (2011) said that technology's influence is ultimately determined by how much power it is given by the people and culture that use it.

\section{Collaborative Learning Model of Digital Media Literacy}

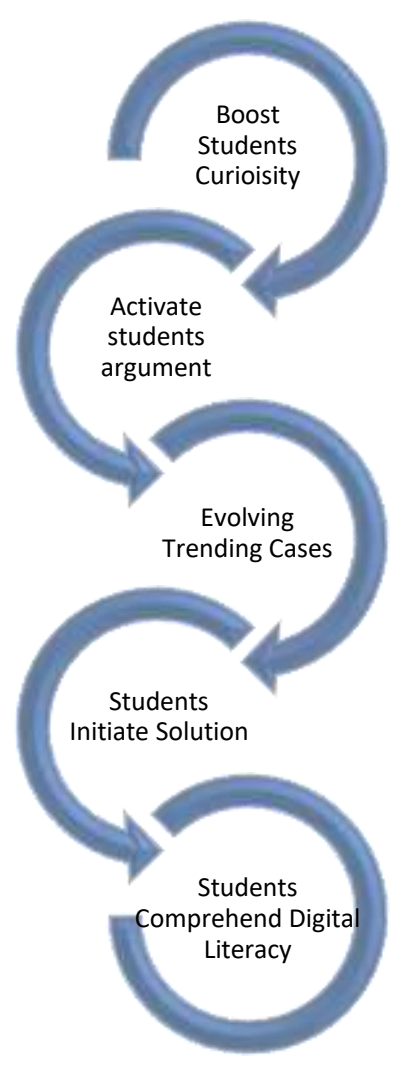

Research Result (2017)

This modification model that started from Boosting, Activating, Evolving, Initiating and Comprehending are the step of collaborative learning to build analytical, critical and smart internet users. Baran (2011) others see technology as more neutral and claim that the way people use technology is what gives it significance. This perspective accepts technology as one of many factors that shape economic and cultural change; technology's influence is ultimately determined by how much power it is given by the people and culture that use it. This disagreement about the power of technology is at the heart of the controversy surrounding the new communication technologies. Technology does have an impact on communication. At the very last it changes the basic elements of communication. What technology does 
not do is relieve us of our obligation to use mass communication responsible and wisely.

Its model teaches the students to be more powerful in the wake of high advances of Internet, rather than manipulated by the technology. Students are not powerless anymore to take more advantages of being internet users. Especially in the aspect of sharing their privacy to the public. Alexander et al (2010), stated that the problem with this word 'privacy' is that it falls short of conveying the really big picture. Privacy isn't just about hiding things. It's about self-possession, autonomy, and integrity. As we move into the computerized world of the twenty first century, privacy will be one of our most important civil rights. But this right of privacy isn't the right of people to close their doors and pull down their windows shades-perhaps because they want to engage in some sort of illicit or illegal activity. It's the right of people to control what details about their lives stay inside their own houses and what leaks to the outside. Today, technology is killing one of our most cherished freedoms. Whether you call this freedom the right to digital selfdetermination, the right to informational autonomy or simply the right to privacy, the shape of our future will be determined in large part by how we understand, and ultimately how we control the threats to this freedom that we face today. Andrew and Ride (2014) have the same things about electronic media also has a bearing upon our use of the term 'new media'. Electronic media privileges the power source of a group of related technologies as its defining feature. At this general level electronic media is also a historical term for grouping together a characteristic element of electronic communication which developed from the late nine tenth century and includes the media of telegraphy, telephone, radio, television, and computing. Electronic media can be considered as a transparent transmission system for the content of previous human communication media, the medium itself being considered a neutral carrying system for sound and image.

Conversely, electronic media can also be considered to profoundly shape its content, so that, for example, radio represents the one way transmission of a disembodied human voice, whereas speech could be considered as embodied in a two-way human interaction. Maschall McLuhan (1964) generalises this understanding to the idea that the content of any medium is always another medium, that is to say that the content of writing is speech and that speech is the content of telegraphy. The term 'electronic media' also connotes many things about the characteristic of the communications which are electronically based. McLuhan also articulates that since the content of any medium is always another medium then the medium is also, always, the message.

\section{CONCLUSION}

Collaborative learning model of digital literacy is actually a participative discussion in a big group to get the understandable of using internet wisely. Students (generation $\mathrm{x}$ and $\mathrm{y}$ ) cannot be treated as the oldest generation to make an effective digital literacy approach. They are the generation with their freedom of speech. This collaborative model tends to give the students free total space to deliver their arguments without being afraid of criticized or mocked. As their minds shaped about their friend's explanation of good and bad in a class discussion, they are started to question the positive aims of using the internet. In a way to have them involving the discussion, I put twelve topics related to the Internet world by keeping myself as a moderator. I neither put myself as pro nor contra during the discussion. Students do the collaborative discussion each other to share their thoughts. This collaboration model will not run well without student's activeness as active internet users. The result of final observation phase shown that the students emphasize the critical evaluation while they are surfing in internet. Critical evaluation means the students think hundreds of times to post or comment on photo, videos, comment and status. This participative model of collaborative learning has successfully guided the students to be smart digital generation.

\section{REFERENCES}

[1] Alexander, Alison. Jarice Hanson and Simson Garfinkel. (2010). Mass Media and Society. McGraw Hill Companies, Inc: New York.

[2] Baran, Stanley J. (2011). Introduction to Mass Communication: Media Literacy and Culture. McGraw Hill Companies, Inc: New York.

[3] Brosdahl, D.J. and Carpenter, J.M. (2011), "Shopping orientations of US males: a generational cohort comparison", Journal of Retailing and Consumer Services, Vol. 18, pp. 548-554.

[4] Carpenter, C. J. (2012). Narcissism on Facebook: Self-promotional and anti-social behavior. Personality and Individual Differences, 52(4), 482486.

[5] Dewdney, Andrew and Peter Ride. (2014). The New Media Handbook. Routledge, New York.

[6] Hannah Gomez Farias, AnnPaskor dan WalterE.Block (Economics Department, Joseph A. Butt, S.J. College of Business, Loyola University New Orleans, New Orleans, Louisiana, USA) (2017)

[7] Immordino-Yang, M.H., Christodoulou, J.A. and Singh, V. (2012), "Rest is not idleness: implications of the brain's default mode for human development and education", Perspectives on Psychological Science, Vol. 7 No. 4, pp. 352-364. 
[8] Michaël Opgenhaffen and An-Sofie Claeys (Institute for Media Studies, Faculty of Social Sciences, KU Leuven, Leuven, Belgium) (2017)

[9] Naomi Amofah-Serwaa and Perpetua S. Dadzie. (Department of Information Studies, University of Ghana). (2015)

[10] Pempek, T.A., Yermolayeva, Y.A. and Calvert, S.L. (2009), "College students' social networking experiences on Facebook", Journal of Applied Developmental Psychology, Vol. 30 No. 3, pp. 227 238.

[11]Park, N., Kee, K.F. and Valenzuela, S. (2009), "Being immersed in social networking environment: Facebook groups, uses and gratifications, and social outcomes", CyberPsychology \& Behavior, Vol. 12 No. 6, pp. 729-733.

[12]Renato Hübner Barcelos and Carlos Alberto Vargas Rossi (Management School, Federal University of Rio Grande do Sul, Porto Alegre, Brazil.) (2014)

[13]Ruth N. Bolton, A. Parasuraman, Ankie Hoefnagels, Nanne Migchels, Sertan Kabadayi, Thorsten Gruber, Yuliya Komarova Loureiro and David Solnet (W.P. Carey School of Business, Arizona State University) (2017)

[14] Supratman, Lucy Pujasari. The Role of Cyber Public Relations in West Java Provincial Government on Symbolization Image Branding. Observasi. Vol. 13 No. 2 (2015).

[15] Supratman (2017). Teenager and Social Media Intelligency. Pikiran Rakyat Daily Newspaper on Thursday, 27 July, 2017

[16] Valkenburg, P.M., Peter, J. and Schouten, A.P. (2006), "Friend networking sites and their relationship to adolescents' well-being and social self-esteem", CyberPsychology \& Behavior, Vol. 9 No. 5, p. 584.Kjfhgkjfdgh

[17] Worley, Will (2017). US Teenager's Family Say He Died After Taking Part in 'Blue Whale' suicide game. Online Newspaper INDEPENDENT. Thursday, 13 July 2017 